\title{
Improvement of Thermal Stability and Tribological Performance of Diamond-Like Carbon Composite Thin Films
}

\author{
Chavin Jongwannasiri, Xianghui Li, Shuichi Watanabe
}

Department of Innovative Systems Engineering, Nippon Institute of Technology, Saitama, Japan.

Email: s3124601@sstu.nit.ac.jp, chavin.jon@outlook.co.th

Received August $3^{\text {rd }}, 2013$; revised September $14^{\text {th }}, 2013$; accepted September $30^{\text {th }}, 2013$

Copyright (C) 2013 Chavin Jongwannasiri et al. This is an open access article distributed under the Creative Commons Attribution License, which permits unrestricted use, distribution, and reproduction in any medium, provided the original work is properly cited.

\begin{abstract}
Diamond-like carbon (DLC) is a metastable amorphous film that exhibits unique properties. However, many limitations exist regarding the use of DLC, for example, its tribological characteristics at high temperature, as well as its limited thermal stability. In this study, silicon/oxygen and silicon/nitrogen co-incorporated diamond-like carbon (Si-O-DLC and Si-N-DLC) films are studied, taking into account the thermal stability and tribological performance of these films compared with pure DLC. All the films were prepared on Si wafers, WC-Co materials, and aluminum foils using a plasma-based ion implantation (PBII) technique using acetylene $\left(\mathrm{C}_{2} \mathrm{H}_{2}\right)$, tetramethylsilane (TMS, $\left.\mathrm{Si}\left(\mathrm{CH}_{3}\right)_{4}\right)$, oxygen $\left(\mathrm{O}_{2}\right)$ and nitrogen $\left(\mathrm{N}_{2}\right)$ as plasma sources. The structure of the films was characterized using Raman spectroscopy. The thermal stability of the films was measured using thermogravimetric and differential thermal analysis (TG-DTA). The friction coefficient of the films was assessed using ball-on-disk friction testing. The results indicate that Si-N-DLC films present better thermal stability due to the presence of Si-O networks in the films. The Si-N-DLC (23 at.\%Si, 8 at.\%N) film was affected using thermal annealing in an air atmosphere with increasing temperature until $500^{\circ} \mathrm{C}$. The film can also resist thermal shock by cycling 10 times between the various temperatures and air atmosphere until $500^{\circ} \mathrm{C}$. Further, Si-O-DLC and Si-N-DLC films exhibit excellent tribological performance, especially the Si-N-DLC (23 at.\%Si, 8 at. $\% \mathrm{~N}$ ) film, which exhibits excellent tribological performance at $500^{\circ} \mathrm{C}$ in an air atmosphere. It is concluded that Si-O-DLC and Si-N-DLC films improve upon the thermal stability and tribological performance of DLC.
\end{abstract}

Keywords: Diamond-Like Carbon; Thermal Stability; Tribological Performance

\section{Introduction}

Diamond-like carbon (DLC) is a metastable amorphous film that exhibits unique properties, such as high hardness, a low friction coefficient, chemical inertness, and high wear and corrosion resistance. Therefore, these films are commonly applied in the protective coatings of cutting tools, magnetic storage disks and biomedical applications [1-3]. The methods used to create DLC films include ion beam assisted deposition (IBAD), magnetron sputtering deposition (MSD), chemical vapor deposition (CVD) and plasma-based ion implantation (PBII) [4-10]. Among these methods, the PBII process is considered as one of the most promising techniques, owing to its ability to uniformly implant and deposit ions into three-dimensional substrates with complex shapes. However, a number of limitations exist regarding the use of DLC. Depending on the environment, the fabrication of this film for tribological applications remains difficult. DLC films exhibit high residual stress values, which lead to poor adhesion to some substrates and limited thermal stability. Many researchers have reported that the introduction of additional elements, such as silicon, nitrogen and various metals, improves the properties of DLC [2].

The incorporation of silicon into DLC has overcome some of the stated drawbacks, including significantly reduced residual stress, while retaining the hardness, improving the thermal stability and delivering a low coefficient of friction that is highly insensitive to changes in humidity [11-13]. When both silicon and oxygen are incorporated into DLC films, significant structural modifications occur. Other authors claim to have obtained a material that consists of an atomic-scale composite of random networks of carbon and silicon in which the carbon network is stabilized by hydrogen, while the silicon 
network is stabilized by oxygen. This type of structure is referred to as a diamond-like nanocomposite (DLN) [1416]. The co-incorporation of silicon/oxygen into DLC films presents interesting mechanical, tribological and optical properties, as well as higher values of thermal stability and fracture toughness [17]. Further, Chen et al. reported that nitrogen-incorporated DLC films were extremely wear resistant with a low coefficient of friction [18]. The reduction in residual stress and the enhancement in thermal stability of nitrogen-incorporated DLC films were previously reported $[19,20]$. However, to our knowledge, results of the silicon/nitrogen co-incorporated DLC films fabricated by PBII using acetylene $\left(\mathrm{C}_{2} \mathrm{H}_{2}\right)$, tetramethylsilane (TMS, $\left.\mathrm{Si}\left(\mathrm{CH}_{3}\right)_{4}\right)$ and nitrogen $\left(\mathrm{N}_{2}\right)$ as plasma sources to improve the thermal stability and tribological performance have not been reported.

In this study, plasma-based ion implantation (PBII) was utilized to prepare Si-O-DLC and Si-N-DLC films with acetylene $\left(\mathrm{C}_{2} \mathrm{H}_{2}\right)$, tetramethylsilane (TMS, $\left.\mathrm{Si}\left(\mathrm{CH}_{3}\right)_{4}\right)$, oxygen $\left(\mathrm{O}_{2}\right)$ and nitrogen $\left(\mathrm{N}_{2}\right)$ as the plasma sources. The deposition was performed as a function of the

$\mathrm{C}_{2} \mathrm{H}_{2}:$ TMS: $\mathrm{O}_{2}$ and $\mathrm{C}_{2} \mathrm{H}_{2}:$ TMS: $\mathrm{N}_{2}$ ratio at a deposition pressure of 2, 4 and $6 \mathrm{~Pa}$. The aim of this study was to investigate the thermal stability and tribological performance of Si-O-DLC and Si-N-DLC coatings. The film properties were investigated using Raman spectroscopy, thermogravimetric and differential thermal analysis (TGDTA), and ball-on-disk friction testing.

\section{Experimental Details}

A schematic of the PBII system used for the deposition of Si-O-DLC and Si-N-DLC films on silicon wafer was previously shown in the literature [21]. Si (100) wafers measuring $0.7 \mathrm{~mm}$ in thickness, tungsten carbide-cobalt (WC-Co) materials, and aluminum foils were used as substrates. The wafers, WC-Co materials, and aluminum foils were sputter cleaned with $\mathrm{Ar}^{+}$for 20 min to remove residual surface contaminants and surface oxides using a negative-pulsed bias voltage of $10 \mathrm{kV}$. Using a negative-pulsed bias voltage of $20 \mathrm{kV}$, the DLC film interlayer was first deposited with $\mathrm{CH}_{4}$ for 60 min to improve the adhesion between the film and the substrate. The deposition of the Si-O-DLC and Si-N-DLC films was performed at a negative-pulsed bias voltage of $5 \mathrm{kV}$, under gaseous mixtures of $\mathrm{C}_{2} \mathrm{H}_{2}:$ TMS: $\mathrm{O}_{2}$ and $\mathrm{C}_{2} \mathrm{H}_{2}:$ TMS: $\mathrm{N}_{2}$ with three different flow rate ratios at 14:1:2, 46:1:2 and $89: 1: 2$ for $180 \mathrm{~min}$. A pulse width of $5 \mu \mathrm{s}$, a pulse delay of $25 \mu \mathrm{s}$, and a pulse frequency of $1 \mathrm{kHz}$ were utilized during the coating process. The deposition pressure was set to 2, 4 and $6 \mathrm{~Pa}$, respectively. The pure DLC film was also deposited onto a $\mathrm{Si}$ substrate and aluminum foils using $\mathrm{C}_{2} \mathrm{H}_{2}$ gas by the same deposition process at a deposition pressure of $2 \mathrm{~Pa}$.
The thermal stability and tribological performance of the Si-O-DLC and Si-N-DLC films were studied using several characterization techniques. The structure of the films was analyzed using Raman spectroscopy (JASCO NRS-1000 DT) at an excitation wavelength of $532 \mathrm{~nm}$ and a spot size of $4 \mu \mathrm{m}$. The Raman spectra in the wave number region were deconvoluted from $1000-1800$ $\mathrm{cm}^{-1}$ into the Gaussian D and G peaks. The integral area under the $\mathrm{D}$ and $\mathrm{G}$ peaks was determined by curve fitting. The thermal stability of the films was performed using coincident thermogravimetric and differential thermal analysis (Rigaku, TG8120). The heating rate was set at a constant value of $20 \mathrm{~K} / \mathrm{min}$, and the samples were heated from room temperature to $800^{\circ} \mathrm{C}$. The measurements were performed under ambient air at room temperature. The tribological performance of the films was assessed using ball-on-disk friction testing (CSEM; Tribotester). In the friction test, a dry sliding test was performed using a ball indenter, AISI440C (SUS440C, diameter of 6.0 $\mathrm{mm}$ ) under a normal applied load of $3 \mathrm{~N}$, a rotation radius of $3 \mathrm{~mm}$, a linear speed of $31.4 \mathrm{~mm} / \mathrm{s}$, and 10,000 frictional rotations. The tests were performed under ambient air at room temperature. The Si-N-DLC (23 at.\% $\%$ Si, 8 at.\%N) films deposited on the WC-Co materials were also used to investigate various annealing temperatures and the thermal shock resistance, and friction coefficient at high temperature. The films were annealed (held at the following temperatures) at $300^{\circ} \mathrm{C}, 400^{\circ} \mathrm{C}$ and $500^{\circ} \mathrm{C}$ in an air atmosphere for 1 hour. The resistance to thermal shock was determined by following the standard procedure (ISO 10545-9), that is, by cycling 10 times between the various temperatures $\left(300^{\circ} \mathrm{C}, 400^{\circ} \mathrm{C}\right.$ and $\left.500^{\circ} \mathrm{C}\right)$ in an air atmosphere. Friction tests were also performed at $500^{\circ} \mathrm{C}$ using the same conditions as mentioned above.

\section{Results and Discussion}

\subsection{Film Structure Based on Raman Spectroscopy}

The Raman spectra of the Si-O-DLC and Si-N-DLC films before annealing are shown in Figure 1. The position of the $G$ peak is related to the bond-angle disorder or the $\mathrm{sp}^{3}$ bonding content, while the $\mathrm{I}_{\mathrm{D}} / \mathrm{I}_{\mathrm{G}}$ ratio is proportional to the ratio of $\mathrm{sp}^{2} / \mathrm{sp}^{3}[22,23]$. These two factors play a major role in assessing the Raman spectra. In particular, the ratio of $\mathrm{sp}^{2} / \mathrm{sp}^{3}$ is one of the most important factors governing the quality of the DLC films. Generally, the likelihood that the properties of the DLC films resemble those of diamond increases when this ratio is low. The Si-O-DLC and Si-N-DLC films fabricated in this experiment exhibit a broad spectrum composed of a $\mathrm{D}$ peak $\left(1350 \mathrm{~cm}^{-1}\right)$ and a $\mathrm{G}$ peak $\left(1580 \mathrm{~cm}^{-1}\right)$, which are similar to the peaks observed in conventional DLC films. As shown in Figure 1, the pure DLC film shows a typical 


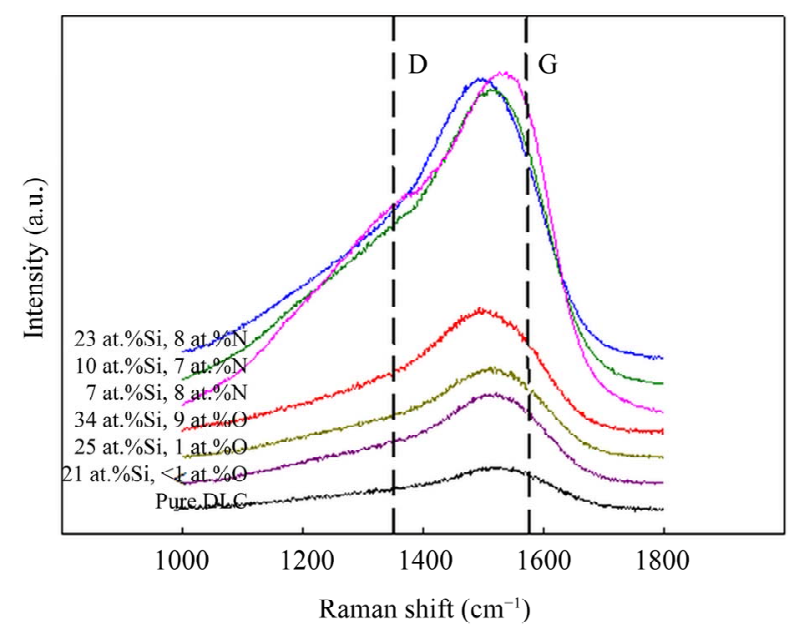

Figure 1. Raman spectra of the Si-O-DLC and Si-N-DLC films before annealing.

diamond-like structure with a $\mathrm{G}$ peak at $1535 \mathrm{~cm}^{-1}$ and an $\mathrm{I}_{\mathrm{D}} / \mathrm{I}_{\mathrm{G}}$ ratio of 0.57 . The $\mathrm{G}$ peak of the Si-O-DLC films shifts from $1530 \mathrm{~cm}^{-1}$ to $1515 \mathrm{~cm}^{-1}$, while the $\mathrm{I}_{\mathrm{D}} / \mathrm{I}_{\mathrm{G}}$ ratio decreases from 0.48 to 0.43 with an increase in the silicon and oxygen contents. Additionally, the G peak of the Si-N-DLC films shifts from $1544 \mathrm{~cm}^{-1}$ to $1510 \mathrm{~cm}^{-1}$, while the $\mathrm{I}_{\mathrm{D}} / \mathrm{I}_{\mathrm{G}}$ ratio decreases from 0.92 to 0.54 with an increase in the silicon content (the nitrogen content varies insignificantly), as shown in Table 1. The microstructure is altered due to the incorporation of silicon, oxygen and nitrogen, as determined based on the shift of the $\mathrm{G}$ peak position to a lower level and the associated decrease in the $I_{D} / I_{G}$ ratio. These results indicate an increase in the number of $\mathrm{sp}^{3}$-bonded atomic sites in amorphous carbon $[24,25]$.

Both the $\mathrm{I}_{\mathrm{D}} / \mathrm{I}_{\mathrm{G}}$ ratio of the Si-N-DLC (23 at.\% $\mathrm{Si}, 8$ at.\%N) film before and after annealing in an air atmosphere and the $\mathrm{I}_{\mathrm{D}} / \mathrm{I}_{\mathrm{G}}$ ratio before and after thermal shock resistance are shown in Figure 2. As shown in Figure 2, the $\mathrm{I}_{\mathrm{D}} / \mathrm{I}_{\mathrm{G}}$ ratio of the films after annealing and thermal shock resistance increases with an increase in temperature. Such an increase of the $I_{D} / I_{G}$ ratio for the films indicates the increase of $\mathrm{sp}^{2}$-bonded clusters in the film, indicating the increase of graphite microcrystallites within the film volume [26]. That is, the increase in $\mathrm{sp}^{2}$ bonds and the formation of $\mathrm{sp}^{2}$ clusters lead to the loss of film hardness and wear resistance. Further, the diamondlike characteristics disappeared in the films annealed and shocked at $600^{\circ} \mathrm{C}$, and the films were completely destroyed at $800^{\circ} \mathrm{C}$. Based on the aforementioned results, the Si-N-DLC (23 at.\%Si, 8 at.\%N) film was affected by thermal annealing in an air atmosphere with an increase in temperature until $500^{\circ} \mathrm{C}$. Additionally, the film can be become resistant to thermal shock by cycling 10 times between the various temperatures and in an air atmosphere until the temperature of $500^{\circ} \mathrm{C}$ is achieved.

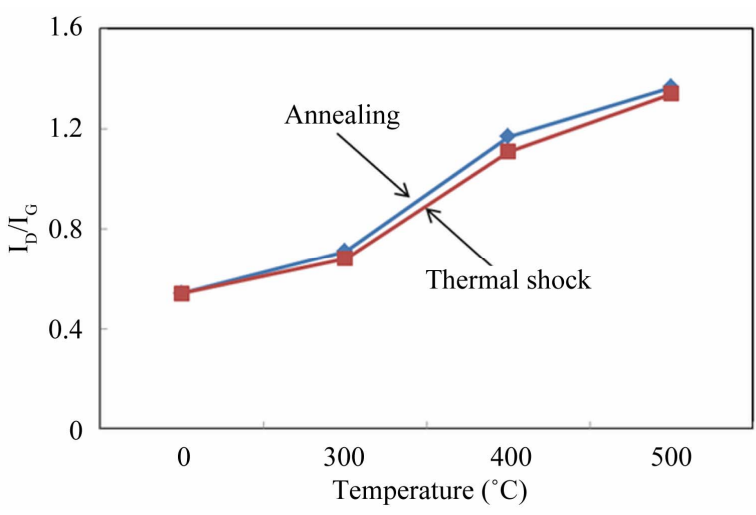

Figure 2. Changes in the $I_{D} / I_{G}$ ratio of the Si-N-DLC (23 at. $\% \mathrm{Si}, 8$ at. $\% \mathrm{~N}$ ) films after annealing and the thermal shock resistance experiments at various temperatures.

\subsection{Thermal Stability of the Films}

The thermal stability of the films was measured by thermogravimetric and differential thermal analysis (TGDTA) under ambient air at room temperature. The changes in weight loss of the Si-O-DLC and Si-N-DLC films were compared with pure DLC film in Figure 3. All the films showed a clear melting point and modest volatility before melting. Yang et al. reported that pure DLC films were completely destroyed over $500^{\circ} \mathrm{C}$, indicating the disappearance of the pure DLC films. However, the Si-O-DLC films were still present until heating to $600^{\circ} \mathrm{C}$, but the diamond-like characteristics disappeared in the films upon heating to $600^{\circ} \mathrm{C}$ [27]. However, the effect of the Si-O network on the thermal stability was no longer observed at higher temperatures.

In this study, all the films were heated to $800^{\circ} \mathrm{C}$. The weight loss of the pure DLC film significantly decreased at temperatures greater than $300^{\circ} \mathrm{C}$, and the film disappeared when heated to $600^{\circ} \mathrm{C}$. Further, the Si-O-DLC film became slightly volatile, and the weight loss significantly decreased at temperatures greater than $450^{\circ} \mathrm{C}$ with an increase in the silicon and oxygen contents. Then, the films disappeared when heated over $650^{\circ} \mathrm{C}$. This indicates that the Si-O-DLC films are not thermally stable when heated over $650^{\circ} \mathrm{C}$. In the case of the Si-N-DLC films, the weight loss gradually volatilized and increased up to $100 \%$. The films continued to decrease significantly over $500^{\circ} \mathrm{C}-550^{\circ} \mathrm{C}$, except the Si-N-DLC $(23$ at. $\% \mathrm{Si}, 8$ at. $\% \mathrm{~N}$ ) film. The weight loss of this film was comparatively volatilized and increased up to $100 \%$, and the film continued to decrease over $670^{\circ} \mathrm{C}$. All of the Si-N-DLC films were still present until heating at $800^{\circ} \mathrm{C}$. It is believed that the increased weight loss of the Si-N-DLC films with an increase in temperature may have occurred due to the adsorption of oxygen from the air into the film surface during heating [27]; this assumption was confirmed by the percentage of the relative atomic contents before and after the thermogravimetric 
Table 1. The relative atomic content and $I_{D} / I_{G}$ of the Si-O-DLC and Si-N-DLC films as functions of gas flow.

\begin{tabular}{|c|c|c|c|c|c|c|}
\hline \multirow{2}{*}{$\begin{array}{l}\text { Pressure } \\
(\mathrm{Pa})\end{array}$} & \multirow{2}{*}{$\begin{array}{c}\text { Gas flow } \mathrm{C}_{2} \mathrm{H}_{2}: \mathrm{TMS}^{\mathrm{O}} \mathrm{O}_{2} \\
(\mathrm{sccm})\end{array}$} & \multicolumn{3}{|c|}{ Relative atomic content (at. \%) } & \multirow{2}{*}{$\begin{array}{l}\text { G Peak } \\
\left(\mathrm{cm}^{-1}\right)\end{array}$} & \multirow{2}{*}{$\mathrm{I}_{\mathrm{D}} / \mathrm{I}_{\mathrm{G}}$} \\
\hline & & $\mathrm{C}$ & $\mathrm{Si}$ & $\mathrm{O}$ & & \\
\hline 2 & $14: 1: 2$ & 57 & 34 & 9 & 1515 & 0.43 \\
\hline 4 & $46: 1: 2$ & 74 & 25 & 1 & 1527 & 0.48 \\
\hline \multirow[t]{3}{*}{6} & $89: 1: 2$ & 78 & 21 & $<1$ & 1530 & 0.48 \\
\hline & Gas flow $\mathrm{C}_{2} \mathrm{H}_{2}:$ TMS: $\mathrm{N}_{2}$ & \multicolumn{3}{|c|}{ Relative atomic content (at. \%) } & & \\
\hline & $(\mathrm{sccm})$ & $\mathrm{C}$ & $\mathrm{Si}$ & $\mathrm{N}$ & & \\
\hline 2 & $14: 1: 2$ & 69 & 23 & 8 & 1510 & 0.54 \\
\hline 4 & $46: 1: 2$ & 83 & 10 & 7 & 1530 & 0.70 \\
\hline 6 & $89: 1: 2$ & 85 & 7 & 8 & 1544 & 0.92 \\
\hline 2 & $\mathrm{C}_{2} \mathrm{H}_{2}$ only & - & - & - & 1535 & 0.57 \\
\hline
\end{tabular}

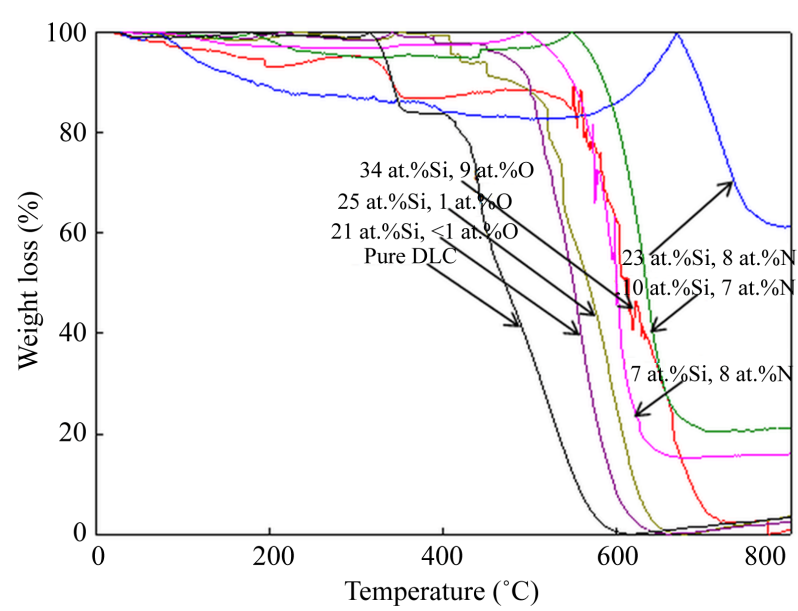

Figure 3. Changes in the weight loss of the Si-O-DLC and Si-N-DLC films as a function of temperature, compared with pure DLC film.

experiments, as shown in Figure 4. Additionally, the transfer of $\mathrm{sp}^{3}$-bonded carbon to $\mathrm{sp}^{2}$-bonded carbon or the growth of $\mathrm{sp}^{2}$-bonded clusters can happen during the heating of Si-N-DLC films in the thermogravimetric experiments. However, the growth of $\mathrm{sp}^{2}$-bonded carbon was suppressed by the Si-O network, which prevented the structural transition of the films during heating, as confirmed by the percentage of the relative atomic contents of the Si-N-DLC (23 at.\%Si, 8 at.\%N) film after performing the thermogravimetric experiments at different temperatures, as shown in Figure 5. Figure 5 indicates the increasing contents of silicon and oxygen with an increase in temperature. Therefore, the presence of the $\mathrm{Si}-\mathrm{O}$ network in the Si-N-DLC films is expected to effectively improve their thermal stability. These results indicate that the silicon/nitrogen co-incorporated films can improve the thermal stability of DLC films.

\subsection{Friction Coefficients of the Films}

The friction coefficients of the Si-O-DLC and Si-N-DLC
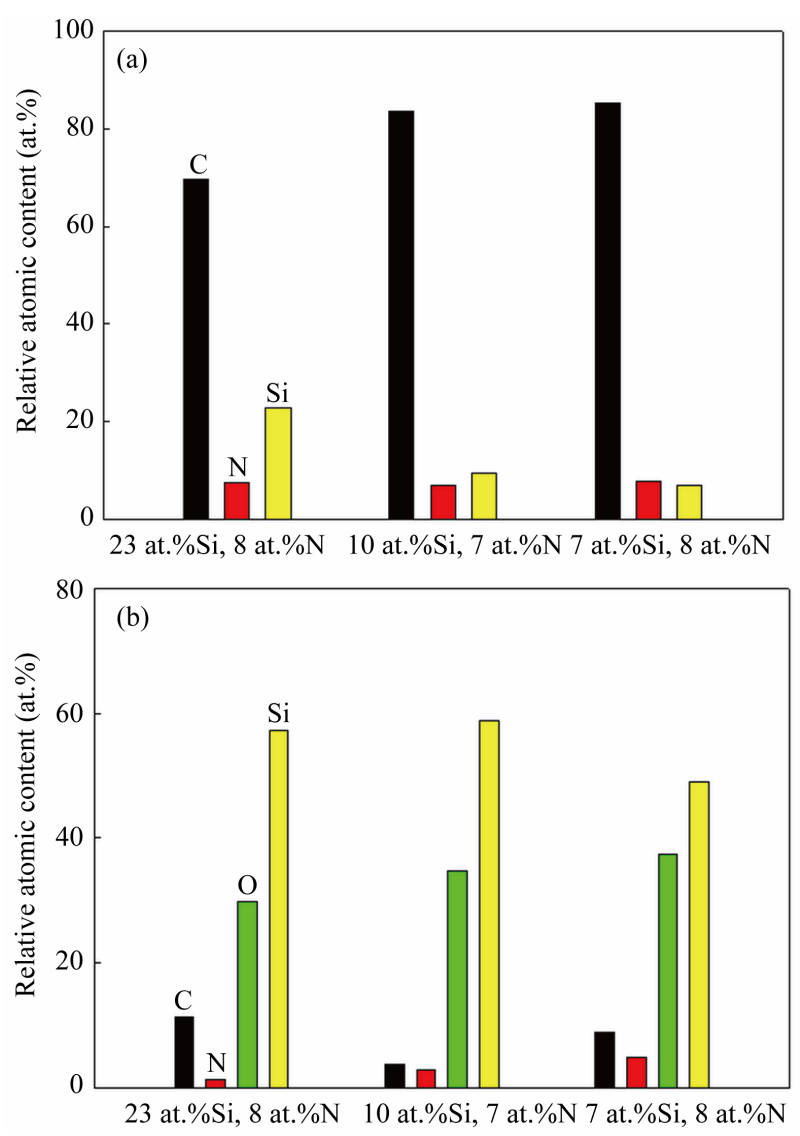

Figure 4. Changes in the atomic concentration of (a) Si-NDLC films before thermogravimetric experiments and (b) Si-N-DLC films after thermogravimetric experiments.

films were measured under ambient air and are shown in Figure 6. The influence of the silicon, oxygen and nitrogen contents on the friction coefficients of the Si-O-DLC and Si-N-DLC films was examined. The pure DLC film had an unstable friction coefficient and failed during the test, while the Si-O-DLC and Si-N-DLC films had stable, lower values of friction coefficients and longer friction endurance due to the incorporation of silicon, oxygen and 


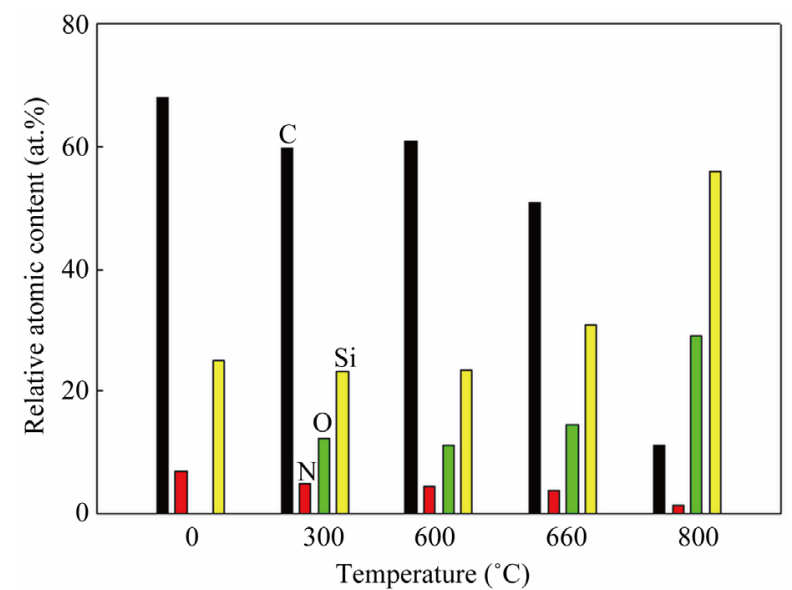

Figure 5. Changes in the atomic concentration of the Si-N-DLC (23 at.\%Si, 8 at.\%N) films after thermogravimetric experiments at different temperatures.

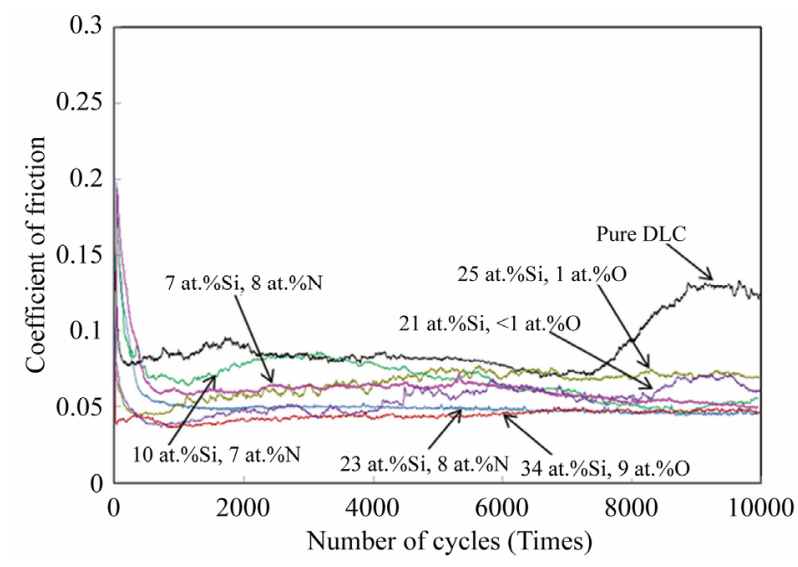

Figure 6. Changes in the friction coefficients of the Si-ODLC and Si-N-DLC films compared with pure DLC film as a function of temperature.

nitrogen. Both the Si-O-DLC (34 at.\%Si, 9 at.\%O) and Si-N-DLC (23 at. $\% \mathrm{Si}, 8$ at. $\% \mathrm{~N})$ films are comparatively stable with a friction coefficient of approximately 0.04 0.05 , which demonstrates the significant improvement in the tribological performance. In the case of the Si-ODLC (34 at.\%Si, 9 at.\%O) film, the result indicates a low friction coefficient, which is related to the formation of silicon-rich oxide debris and the transfer of silicon oxide layers on the steel ball surfaces [28]. This silicon oxide layer prevents direct contact between the film and ball when sliding, resulting in the low friction forces. Additionally, in the case of the Si-N-DLC (23 at.\%Si, 8 at.\%N) film, the result indicates a low friction coefficient due to the incorporation of silicon and nitrogen [29]. However, the nitrogen content may be less influential than the silicon content, due to the minimal difference in the nitrogen content of the Si-N-DLC films. Further, the other Si-O-DLC and Si-N-DLC films have higher friction coefficients than the films described above, although the coefficients are still lower than that of pure DLC. These results indicate that the silicon/oxygen and silicon/nitrogen co-incorporated films can improve the tribological performance of DLC films.

In the case of the high temperature condition, the friction coefficient of the Si-N-DLC (23 at.\%Si, 8 at.\%N) film is compared with that of the non-coated Si-N-DLC film in Figure 7, measured at $500^{\circ} \mathrm{C}$. As shown in Figure 7, the Si-N-DLC film is comparatively stable with a friction coefficient of approximately 0.02 , which demonstrates the significant improvement in the tribological performance achieved at high temperature. However, the non-coated Si-N-DLC film is not stable and has a friction coefficient of approximately 0.9 (measured until approximately 2000 cycles). This result indicates the significant difference in the friction coefficients between the coated and non-coated films. This phenomenon may be the result of the presence of a Si-O network in the film, which is expected to be an effective approach to enhancing the thermal stability of the films. Consequently, it is assumed that the co-incorporation of silicon/nitrogen into the DLC film yields good tribological performance for protective coating applications in a high-temperature environment in an air atmosphere in comparison with non-coated films.

\section{Conclusion}

Si-O-DLC and Si-N-DLC films were successfully prepared on Si (100) wafers, WC-Co materials, and aluminum foils using the PBII technique. The films were investigated for the effects of silicon, oxygen and nitrogen contents on the thermal stability and tribological performance using Raman spectroscopy, thermogravimetric and differential thermal analysis (TG-DTA), and ball-ondisk friction testing. The Si-O-DLC and Si-N-DLC films possess a diamond-like structure due to the decreasing value of $\mathrm{I}_{\mathrm{D}} / \mathrm{I}_{\mathrm{G}}$ with an increase in the silicon content.

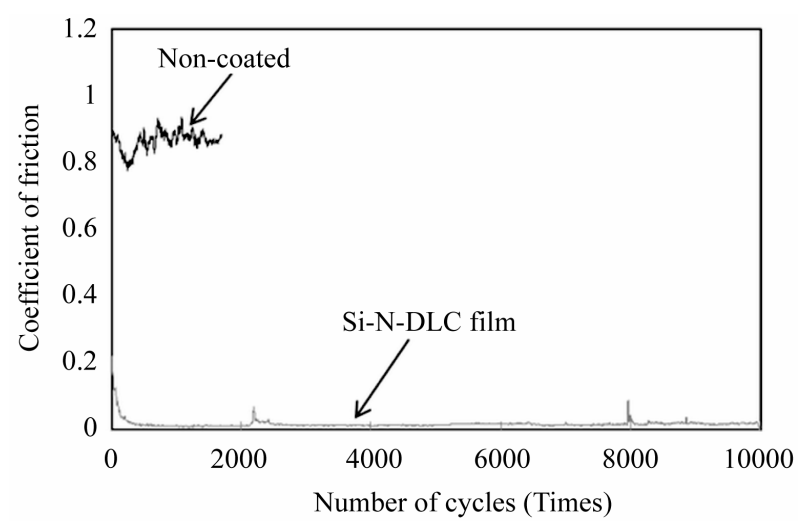

Figure 7. The friction coefficients of WC-Co coated Si-NDLC (23 at.\%Si, 8 at.\%N) film compared with non-coated Si-N-DLC film, measured at $500^{\circ} \mathrm{C}$. 
Additionally, the Si-N-DLC (23 at.\%Si, 8 at.\%N) film was affected by thermal annealing in an air atmosphere, and the film can resist the thermal shock after cycling 10 times between the various annealing temperatures and air atmosphere until reaching $500^{\circ} \mathrm{C}$. Further, the Si-N-DLC films possess higher thermal stability than the pure DLC and Si-O-DLC films due to the presence of Si-O networks in the films. The Si-O-DLC and Si-N-DLC films also exhibit lower friction coefficients than pure DLC film. Comparing the Si-O-DLC and Si-N-DLC films, the friction coefficient insignificantly varies. Further, the Si-N-DLC (23 at.\%Si, 8 at.\%N) film shows good tribological performance at $500^{\circ} \mathrm{C}$ when compared with the non-coated substrate. Due to the aforementioned reasons, the Si-N-DLC films present with high thermal stability and excellent tribological performance. Thus, Si-N-DLC films can play an important role in high-temperature applications.

\section{Acknowledgements}

This research was supported by Japan Society for the Promotion of Science (JSPS KAKENHI), Grant-in-Aid for Scientific Research (C) 22560147.

\section{REFERENCES}

[1] S.-J. Cho, J.-W. Chung and K.-R. Lee, "Characterization of the Mechanical Properties of Diamond-Like Carbon Films," Diamond and Related Materials, Vol. 14, No. 8, 2005, pp. 1270-1276.

http://dx.doi.org/10.1016/j.diamond.2004.11.034

[2] J. Robertson, "Diamond-Like Amorphous Carbon," Materials Science and Engineering Reports, Vol. 37, No. 4-6, 2002, pp. 129-281.

http://dx.doi.org/10.1016/S0927-796X(02)00005-0

[3] R. A. Singh, E.-S. Yoon, H. J. Kim, H. Kong, S.-J. Park and K.-R. Lee, "Friction Behaviour of Diamond-Like Carbon Films with Varying Mechanical Properties," Surface and Coatings Technology, Vol. 201, No. 7, 2006, pp. 4348-4351. http://dx.doi.org/10.1016/j.surfcoat.2006.08.055

[4] C. M. Cotell and J. K. Hirvonen, "Effect of Ion Energy on the Mechanical Properties of Ion Beam Assisted Deposition (IBAD) Wear Resistant Coatings," Surface and Coatings Technology, Vol. 81, No. 1, 1996, pp. 118-125. http://dx.doi.org/10.1016/0257-8972(95)02650-9

[5] Y. Funada, K. Awazu, H. Yasui and T. Sugita, "Adhesion Strength of DLC Films on Glass with Mixing Layer Prepared by IBAD," Surface and Coatings Technology, Vol. 128-129, 2000, pp. 308-312.

http://dx.doi.org/10.1016/S0257-8972(00)00591-0

[6] M. Günther, I. Bialuch, S. Peter, K. Bewilogua and F. Richter, "High Rate Deposition of Hard a-C:H Films Using Microwave Excited Plasma Enhanced CVD," Surface and Coatings Technology, Vol. 205, No. S2, 2011, pp. S94-S98. http://dx.doi.org/10.1016/j.surfcoat.2010.12.047
[7] M. Ikeyama, S. Miyagawa, Y. Miyagawa, Y. Hayakawa and T. Miyajima, "DLC Coatings on Inner Walls of PET Bottles by a Simplified PBII Technique," Surface and Coatings Technology, Vol. 201, No. 19-20, 2007, pp. 8112-8115.

http://dx.doi.org/10.1016/j.surfcoat.2006.02.064

[8] J. X. Liao, Z. Tian, J. Xu, L. Jin and H. G. Yang, "The Effect of $\mathrm{H}_{2} / \mathrm{C}_{2} \mathrm{H}_{2}$ Ratio on the Structure and Tribological Properties of Carbon Thin Films Prepared by PBII," Surface and Coatings Technology, Vol. 201, No. 6, 2006, pp. 2871-2877.

http://dx.doi.org/10.1016/j.surfcoat.2006.05.038

[9] J. Noshiro, S. Watanabe, T. Sakurai and S. Miyake, "Friction Properties of Co-Sputtered Sulfide/DLC Solid Lubricating Films," Surface and Coatings Technology, Vol. 200, No. 20-21, 2006, pp. 5849-5854.

http://dx.doi.org/10.1016/j.surfcoat.2005.08.147

[10] A. Pardo and C. Gómez-Aleixandre, "Metal Incorporation Strategies in DLC (Fullerene-Like) Thin Films Grown by ECR-CVD," Vacuum, Vol. 85, No. 12, 2011, pp. 11401143. http://dx.doi.org/10.1016/j.vacuum.2011.03.001

[11] S. S. Camargo Jr., A. L. Baia Neto, R. A. Santos, F. L. Freire Jr., R. Carius and F. Finger, "Improved HighTemperature Stability of Si Incorporated a-C:H Films," Diamond and Related Materials, Vol. 7, No. 8, 1998, pp. 1155-1162. http://dx.doi.org/10.1016/S0925-9635(98)00165-4

[12] A. L. Baia Neto, R. A. Santos, F. L. Freire Jr., S. S. Camargo Jr., R. Carius, F. Finger and W. Beyer, "Relation between Mechanical and Structural Properties of Silicon-Incorporated Hard a-C:H Films," Thin Solid Films, Vol. 293, No. 1-2, 1997, pp. 206-211. http://dx.doi.org/10.1016/S0040-6090(96)08948-1

[13] K. Oguri and T. Arai, "Friction Coefficient of Si-C, Ti-C and Ge-C Coatings with Excess Carbon Formed by Plasma-Assisted Chemical Vapour Deposition," Thin Solid Films, Vol. 208, No. 2, 1992, pp. 158-160. http://dx.doi.org/10.1016/0040-6090(92)90635-O

[14] V. F. Dorfman, "Diamond-like nanocomposites (DLN)," Thin Solid Films, Vol. 212, No. 1-2, 1992, pp. 267-273. http://dx.doi.org/10.1016/0040-6090(92)90532-G

[15] D. J. Kester, C. L. Brodbeck, I. L. Singer and A. Kyriakopoulos, "Sliding Wear Behavior of Diamond-Like Nanocomposite Coatings," Surface and Coatings Technology, Vol. 113, No. 3, 1999, pp. 268-273. http://dx.doi.org/10.1016/S0257-8972(99)00003-1

[16] D. Neerinck, P. Persoone, M. Sercu, A. Goel, D. Kester and D. Bray, "Diamond-Like Nanocomposite Coatings (a-C:H/a-Si:O) for Tribological Applications," Diamond and Related Materials, Vol. 7, No. 2-5, 1998, pp. 468471. http://dx.doi.org/10.1016/S0925-9635(97)00201-X

[17] W. J. Yang, T. Sekino, K. B. Shim, K. Niihara and K. H. Auh, "Microstructure and Tribological Properties of $\mathrm{SiO}_{\mathrm{x}} / \mathrm{DLC}$ Films Grown by PECVD," Surface and Coatings Technology, Vol. 194, No. 1, 2005, pp. 128-135. http://dx.doi.org/10.1016/j.surfcoat.2004.05.023

[18] M. Y. Chen, X. Lin, V. P. Dravid, Y. W. Chung, M. S. Wong and W. D. Sproul, "Growth and Characterization of C-N Thin Films," Surface and Coatings Technology, 
Vol. 54-55, Pt. 2, 1992, pp. 360-364. http://dx.doi.org/10.1016/S0257-8972(07)80048-X

[19] H. L. Bai and E. Y. Jiang, "Improvement of the Thermal Stability of Amorphous Carbon Films by Incorporation of Nitrogen," Thin Solid Films, Vol. 353, No. 1-2, 1999, pp. 157-165. http://dx.doi.org/10.1016/S0040-6090(99)00421-6

[20] D. F. Franceschini, C. A. Acheter and F. L. Freire, "Internal Stress Reduction by Nitrogen Incorporation in Hard Amorphous Carbon Thin Films," Applied Physics Letters, Vol. 60, No. 26, 1992, pp. 3229-3231. http://dx.doi.org/10.1063/1.106702

[21] C. Jongwannasiri, N. Moolsradoo, A. Khantachawana, P. Kaewtatip and S. Watanabe, "The Comparison of Biocompatibility Properties between Ti Alloys and Fluorinated Diamond-Like Carbon Films," Advances in Materials Science and Engineering, Vol. 2012, 2012, Article ID: 724126. http://dx.doi.org/10.1155/2012/724126

[22] M. A. Capano, N. T. McDevitt, R. K. Singh and F. Qian, "Characterization of Amorphous Carbon Thin Films," Journal of Vacuum Science and Technology A, Vol. 14, No. 2, 1996, pp. 431-435. http://dx.doi.org/10.1116/1.580101

[23] J. Qi, J. B. Luo, S. Z. Wen, J. Wang and W. Z. Li, "Mechanical and Tribological Properties of Non-Hydrogenated DLC Films Synthesized by IBAD," Surface and Coatings Technology, Vol. 128-129, 2000, pp. 324-328. http://dx.doi.org/10.1016/S0257-8972(00)00598-3

[24] D. Beeman, J. Silverman, R. Lynds and M. R. Anderson,
"Modeling Studies of Amorphous Carbon," Physical Review B, Vol. 30, No. 2, 1984, pp. 870-875.

http://dx.doi.org/10.1103/PhysRevB.30.870

[25] L. Y. Chen and F. C.-N. Hong, "Surface Tension Studies of $(\mathrm{Si}, \mathrm{N})$-Containing Diamond-Like Carbon Films Deposited by Hexamethyldisilazane," Diamond and Related Materials, Vol. 12, No. 3-7, 2003, pp. 968-973.

[26] F. L. Freire Jr., G. Mariotto, R. S. Brusa, A. Zecca and C. A. Achete, "Structural Characterization of Amorphous Hydrogenated Carbon and Carbon Nitride Films Deposited by Plasma-Enhanced CVD," Diamond and Related Materials, Vol. 4, No. 4, 1995, pp. 499-502. http://dx.doi.org/10.1016/0925-9635(94)05211-5

[27] W. J. Yang, Y.-H. Choa, T. Sekino, K. B. Shim, K. Niihara and K. H. Auh, "Thermal Stability Evaluation of Diamond-Like Nanocomposite Coatings," Thin Solid Films, Vol. 434, No. 1-2, 2003, pp. 49-54. http://dx.doi.org/10.1016/S0040-6090(03)00466-8

[28] S. H. Yang, H. Kong, K.-R. Lee, S. Park and D. E. Kim, "Effect of Environment on the Tribological Behavior of Si Incorporated Diamond-Like Carbon Films," Wear, Vol. 252, No. 1-2, 2002, pp. 70-79. http://dx.doi.org/10.1016/S0043-1648(01)00856-0

[29] B. Saha, E. Liu, S. B. Tor, N. W. Khun, D. E. Hardt and J. H. Chun, "Replication Performance of Si-N-DLC-Coated Si Micro-Molds in Micro-Hot-Embossing," Journal of Micromechanics and Microengineering, Vol. 20, No. 4, 2010, pp. 1-8. http://dx.doi.org/10.1088/0960-1317/20/4/045007 